\title{
The Theoretical Basis and Importance of Maker Education
}

\author{
PEI Ying ${ }^{1,2}$ \\ 1. Business School, Malaysia University of Science and Technology, Kuala Lumpur, 47810; \\ 2. School of Business, Xi'an Siyuan University \\ Xi'an Shaanxi, 710038
}

\begin{abstract}
Maker education originating from maker movement is a deep combination of maker culture and education. Based on the innovative education, project learning, the whole person education of maker education has attracted close attention from the academic circle. The development of maker education has become an important strategic way to deepen education reform and promote quality education. This paper studies the origin of maker education, analyzes the evolutionary process from maker movement, maker culture to maker education, and summarizes the characteristics of maker education. This paper explores the theoretical basis rooted of maker education. Finally, it summarizes the importance of the development of maker education.
\end{abstract}

Keywords-Maker Education; Makerspace; Constructionism Theory; Situation Learning

\section{INTRODUCTION}

In 2012, the concept of maker enters into the global public view formally. The long tail theory inventor Chris Anderson (2012) [1] pointed out: The combination of digital manufacturing and personal manufacturing, which brings an epoch-making creation of the maker movement. The maker movement is regarded as an important driver of economic and social transformation.

In the new economic era, maker movement has become a new booster to lead the global industrial revolution. The maker movement is a global revolution in technology and innovative learning, which has had an important and farreaching impact on education in the world, and has become one of the digital strategies for education reform in the world. As the incubator base of the maker movement, the construction of the makerspace is also valued by governments of various countries, which is regarded as one of the effective ways to promote educational reform and cultivate students' creativity by educators. Makerspaces solved the frontier issues of innovation, design and entrepreneurship and so on, which would improve students' creativity and practical skills [2](Kueti et al., 2014). Therefore, students not only develop the abilities to discover problems, analyze problems and solve problems, but also make it easier to maintain the passion of learning and enhance the confidence of learning, while all these qualities are important components of students' creativity. The rapid development of global makerspace provides a new opportunity for the development of education innovation, which is a research hotspot in the field of global educational technology research.

\section{THE EVOLUTION OF MAKER, MAKER MOVEMENT, MAKERSPACE}

In 2005, Dale Dougherty, Editor-in-Chief of the American magazine "Maker", launched the Maker Movement in the United States, the purpose of which was to "encourage creators who like high-tech to better participate in practice and turn ideas into reality" and "make creation popularization". Dale Dougherty organized the Maker Faire event in San Francisco, USA since 2006. In 2017, there were more than 190 independent maker conferences with millions of participators in various parts of the world, including 30 largescale maker activities in Tokyo of Japan, Rome of Italy, Shenzhen of China, Paris of France and Seoul of South Korea and so on, which became the largest Maker Movement celebration in the world of creativity show, innovation and creativity, and the promotion of maker culture, and initiated reforms from education to culture in the global, promoting the development of Maker Movement.

The maker movement originated from the advancement of high technology and the development of new digital manufacturing technologies, such as robotics, wearable electronic devices, 3D printing and open source hardware and so on. It is a trend of producing products by oneself or cooperate with others, and refers to the makers who love new technologies and have courage to practice innovation share ideas and exchange technologies in virtue of maker space", and strive to turn creative ideas into reality. The maker movement includes three core elements: creation, maker space and makers[3] (Halverson \& Sheridan, 2014).

Dale Dougherty[4] (Honey \& Kanter, 2016) believed that maker was a group of people with specific attributes, who insisted on sharing and disseminating knowledge, and tried to turn ideas into reality. Maker as a person who does not aim for profit but driven by personal interests and hobbies to turn ideas into reality.

Makers is not only a group of people who love or enjoy innovation, but also a kind of culture, a kind of attitude and a kind of learning style[5] (Yang, 2015). By this token, maker refers to those who are brave to innovate and strive to turn their ideas into reality, who need to have a certain level of 
knowledge and awareness of innovation, practice, sharing and communication. This group has obvious characteristics: innovation is its primary feature, that is, creative thinking as the core, emphasizing their ability to develop and design products and the spirit of challenge; The second is the feature of sharing, emphasizing that they are willing to cooperate, communicate with others and jointly turn ideas into reality with the spirits of openness and participation; Finally, it is the feature of practice, emphasizing the combination of theory and practice through hands-on operations, achieving unity of knowledge and practice, which embodies the practical spirit of "learning in the action".

As the carrier of maker movement, makerspace usually refers to the place where people with common interests in various fields gather to share ideas, share information, conduct cooperation and create activities. Maker space is a venue for makers to get together, act and cooperate, and is a laboratory and studio for open communication, and a physical space carrier for makers to conduct creative innovation sharing, transformation and realization. The well-known makerspaces in abroad include Artisan's Asylum, and Tech Shop in America, Chaos Computer Club in Germany and Access Space in the United Kingdom, etc. The famous makerspaces in domestic include Shenzhen Firewood Space, Beijing Makerspace, Tsinghua University Makerspace and Wenzhou Middle School Makerspace, etc.

\section{FEATURES OF MAKER EDUCATION}

\section{A. Advanced technical equipment support system}

The rapid popularity of makerspace benefits from the development of digital technology. In particular, the applications of open source software and hardware provide technical support for the popularity of makerspace. For example, the open source hardware Arduino provides makers with a low-cost, fast and efficient electronic prototype platform, and an open source and free makerspace ecosystem built by Arduino as the main tool has become a common practice. The technical equipment that makerspace usually has is: 3D printers, open source software and hardware, wearable devices, laser cutting machines, intelligent robots, CNC machine tools and so on. It is high-tech equipment that gives makers the power to invent and create.

The technical configuration of makerspace in universities is the result of the integration of various professional technologies and resources. To build a highly efficient makerspace, it is necessary to equip the material and equipment required for makers' creative activities, in order to break through professional boundaries and convert students' ideas into products in a commercialized way.

\section{B. Open source, free and sharing maker culture}

The most distinctive feature of makerspace is not the equipment that represents cutting-edge technology, but the maker culture that respects freedom, open source, and sharing spirit in the space. Maker culture brings together makers to communicate freely, learn collaboratively, and use open source software and hardware resources to turn ideas into reality. Participants in the project are mainly driven by interest and expertise to create ideas, which is more conducive to the cultivation of creativity and the improvement of innovation efficiency.

The operating mode of makerspace is prone to form a loose informal organization form with "maker projects" as the unit. Many "maker projects" require cross-multidisciplinary knowledge, and interdisciplinary project teams with different professional backgrounds, by the exchange and sharing of knowledge and ideas, to promote the transfer and learning of interdisciplinary knowledge, thus creating a new knowledge system, and gradually forming a maker culture paradigm with freedom and sharing characteristics in makerspace. Under this concept, makerspace needs to create an open and free atmosphere, giving active and positive support and encouragement to makers, letting students experience happiness and self-confidence created and shared in makerspace and the intrinsic value of completing "maker projects", thus shaping a healthier personality through the enjoyment of manufacturing process and collaboration with others.

\section{Quasi-real situation learning mode}

Situational learning theory states that "only when a person devotes himself fully to the practice of a real situation can it maximally stimulate the learner's willingness to learn and truly feel the value and meaning of learning" [6] (Lave \& Wenger, 1991). Situational learning emphasizes the process of knowledge construction in real and meaningful situations. It has the following characteristics. First, the starting point of the learning process is to solve the real problems, guide students to actively think and construct knowledge through practical problems, which will help improve the students' ability to analyze problems, solve problems, and reverse thinking. Second, students are no longer passive recipients of knowledge, but actively explore and discover knowledge, which is beneficial to the improvement of students' creative thinking [7] (Kolb, 1984). Not complex as a real factory, makerspace provides a quasi-real situation exploration platform for makers and builds a learning method of design practice based on the real situation. The learning objectives are clearer and can effectively stimulate students' learning interest and potential. The new knowledge constructed by students in makerspace is hidden in the "maker projects" based on real situation. Students need to integrate various resources and seek solutions to the phenomena or problems through hands-on practice and communication and collaboration, to complete challenging "maker projects", thus truly achieving the teaching philosophy of "unity of knowledge and practice, hands and brains". 


\section{FUNDAMENTAL THEORIES OF MAKERSPACES}

\section{A. Pragmatism "Learning by Doing” theory}

John Dewey was an American pragmatist philosopher and educator, who founded the pragmatic education ideology. "Learning by Doing" is the core point of Dewey's pragmatic education theory. The so-called "Learning by Doing" means that real learning is not only the process of acquiring information through the classroom, but more importantly, learning in complex social practices [8] (Dewey, 1997), so that learners can obtain more valuable knowledge in the meaningful tasks and activities.

Tao Xingzhi, a Chinese educator, inherited and developed Dewey's educational thoughts, while combined China's educational practice, he pointed out that Chinese education now: "A common problem in Chinese education is that learning people who use the brain not to use their hands, and not learning those who use hands to use the brain, so nothing can be done". The education model of makerspaces emphasize "Learning by Doing" and uses specific projects as the carrier to allow students to realize the fun of collaborative sharing through hands-on operations in the real maker projects, and to realize learning and skills of knowledge in the process of creation, making students to become a creator and cultivating their innovative thinking and ability of solving problems independently, while ultimately achieve "enhancement of creativity" and "highly knowledge both in learning and practice" [9] (Martinez, 2013). The university makerspaces just provides students with a platform that can achieve "Learning by Doing". The makerspaces emphasizes that students should be able to improve their ability to find problems and solve problems during producing works. This kind of personalized hands-on practical ability and solving problems ability are exactly what China's education currently ignores and needs to be strengthened. Makerspaces provide a new solution to the real problems of high scores but low ability in China's education and lack of creative talents, which is the inheritance and development of the idea of "Learning by Doing".

\section{B. Constructionism theory}

Constructionism was proposed by Seymour Papert, the tenured professor of Massachusetts Institute of Technology in America, the founder of education informationization, "the father of the maker movement" and the inventor of LOGO language, on the basis of Jean Piaget's constructivism. Constructionism supports the view of constructivism, that is, learners are active knowledge builders, while learning is the process of sharing and constructing knowledge, but it also more emphasizes hand-made constructing external, special and shareable works through detailed materials to construct his own knowledge system [10] (Seymour, 1980). Constructionism also established its own basic ideas: Focus on student-centered teaching, students are transferred from passive recipients of external stimuli into active constructors of knowledge; Focus on teaching in real situations, emphasizing the provision of adequate resources to support student learning, and need to make full use of various modern resources to build more realistic learning situations for students; Focus on the important role of collaborative learning on construction, and to complete the construction of knowledge based on the sharing of collective thinking achievements.

The theoretical view of constructivism provides strong evidence for learning behavior in the makerspaces. Constructivism believes that students can build new knowledge systems on the basis of existing knowledge reserves and experiences by collaborative sharing with each other. Makerspaces provide a most suitable place for knowledge sharing and the constructing, providing sufficient space and opportunities for students to build their own knowledge system. In the process of completing the makerspace project, each student has his/her own best skills and can contribute to share knowledge and complete tasks, which fully reflects the important role of collaboration in knowledge construction.

The learning mode of makerspace is consistent with the constructivism concept that allowing students to actively participate in the creative works, meanwhile emphasizing the students to share their own knowledge, conducting the concept of knowledge construction through production. The essence of constructivism learning process is "learning by making", that is, learning through the students' production of the works. The production-based learning is the most needed and most humanized way of learning because the production and creation behavior itself are the direct evidence of knowledge construction.

The new tools and equipments used in university makerspaces reduced the barriers for students to create, enabling students to truly move from consumers of knowledge to creators of knowledge, and upgrade "learning by doing" to "learning by creating". Constructivism pays attention to the emergence and resolution of problems, and emphasizes that students should learn in an environment that is similar to the problems of the real world, so as to promote their ability to solve problems and increase their knowledge absorptive capacity [11] (Jonassen, Howland \& Moore, 2002). The learning mode of makerspace is based on experiential learning in real situations. Although it is not as complex as a real factory, it provides students with a quasi-situation learning environment, focusing on cultivating students' hands-on abilities and creative thinking, which is highly consistent with the learning concept of constructivism.

The teaching methods and learning methods advocated by constructivism have far-reaching significance for students creativity. First of all, constructivism emphasizes that learning is an active process rather than a passive process. Students are the main part of teaching, while teachers are no longer the indoctrinators of knowledge and dominant of teaching, but the instructors of constructing knowledge. The construction of new knowledge for students should be started from its original knowledge and respect the individual differences of each student. Teachers should create more vivid real situations to help students acquire knowledge, encourage students to create new works, and students' initiative learning should be supported and encouraged, which is more conducive to the cultivation and promotion of students' creativity. 


\section{Space production theory}

Lefebvre was committed to the study of "space" issues. In "The Production of Space", he put forward the core concept of the social production of space [12] (Lefebvre, 1991). Its basic meaning is that "Space is a product of society". Space has its material properties, but it is by no means a material existence that has nothing to do with human beings, human practice and social relations. It is precisely because people are involved space, then it is viable and alive, and shows its value and significance. The materiality of space refers to be experienced and be produced. The social nature of space refers to the production process through human activities [13] (Carp, 2008). Lefebvre believed that any kind of space can be conceptually divided into perceived space, conceived space, and lived space. The perceived space is a space with physical form, referring to those matters that can be seen and touched, pointing to the materiality of space, which can be measured accurately by using certain tools; The conceived space is the space of scientists and planners, representing the invisible rights, control and knowledge, and the constructors of space govern and dominate the process of real space construction through the control of space knowledge systems; The lived space refers to the space of users, representing the space that is ruled and truly experienced, which is qualitative, fluid and dynamic [14] (Merrifield, 2006).

According to space production theory, the makerspace is not static and dead, but dynamic, productive and social. Makerspace can also be divided into three spatial structures. The perceived space refers to the physical environment of the makerspace, which mainly refers to the equipment and facilities of the makerspace, considering whether the it is equipped with the most advanced experimental equipment and whether there is a spacious and comfortable place; The conceived space refers to the construction of makerspace by its planners, especially teachers, which mainly involves the makerspace teaching guiding principles, teaching modes and teachers' creativity, etc. The lived space refers to the real learning experience of student in makerspaces, which mainly involves the learning mode and learning autonomy of students.

\section{CONCLUSION}

Maker education not only pays attention to the quality of various subjects, but also pays more attention to the learners' ability of innovation, and "emphasizing on creativity" has become its core educational goal. In recent years, as a new education model of focusing on cultivating students' innovative thought and creativity, maker space has received more and more attention in both the United States and China. The core of the construction concept of makerspace is to cultivate students' creative awareness, creative thought and creativity through hands-on practice, and to help students to relieve the constraints coming from the classroom. Maker space can promote students' creative realization, improve students' creativity, improve the success rate and feasibility of results transformation, and reduce students' entrepreneurial risk.

Zhu Wenli, director of education affairs at the Corporate Affairs Division of Intel China Ltd., once pointed out: "If students learn and create in a very independent and open space with technical support and teachers' support, they can give full play to their creativity. Such an environment can better inspire their interest and cultivate their creativity and hands-on capabilities." In 2014, Dale Dougherty, founder of "Maker" magazine, led the America Maker Education Initiative, pointing out that the core task of makerspace is to create more manufacturing opportunities for young people, and to let every young person become a maker through hands-on manufacturing, building self-confidence and cultivating creativity. The 2015 Higher Education Horizon Report released by the New Media Alliance of the United States showed that makerspace was selected as the top 12 key technologies affecting basic education in the next 5 years, and was considered as strategic strategy for enhancing students' practical ability, exploring force and creativity, and promoting the learning reform of higher education, which would bring profound changes to the teaching of college teachers and the learning of student, as well as would be adopted in many universities around the world in the next 2-3 years [15] (Johnson et al., 2015)

\section{ACKNOWLEDGMENT}

Author:Pei Ying (1980- ), female, Jilin City, Jilin Province, China. Ph.D. student of Malaysia University of Science and Technology, Associate Professor of Xi'an Siyuan University, research direction: education innovation.

\section{REFERENCES}

[1] Anderson, C. (2012). Makers: The New Industrial Revolution. New York: Crown

[2] Kueti, Steven, R., Kurti, Debby, L., Fleming \& Laura. (2014). "The Philosophy of Educational Makerspaces", Teacher Librarian, Vol.41 No.5, pp. 8-11.

[3] Halverson, E.R., and Sheridan, K.M. (2014). "The Maker Movement in Education", Harvard Educational Review, Vol.84 No.4, pp. 495-504.

[4] Honey, M., and Kanter, D.E. (2016). Design, Make, Play: Growing the Next Generation of STEM Innovators. Routledge.

[5] Yang Xianmin. (2015). "The Value Potential and Controversy of Maker Education", Modern Distance Education Research, Vol.12 No.2, pp. 2334.

[6] Lave, J., \& Wenger, E. (1991). Situated Learning: Legitimate Peripheral Participation. England, Cambridge: Cambridge University Press.

[7] Kolb D. (1984). "Experiential Learning: Experience As the Source of Learning and Development". Pearson Schweiz Ag, Vol.1 No.3, pp. 1617.

[8] John Dewey. (1997). Experience and Education, New York: Free Press.

[9] Martinez, S.L., Stager, G.S. (2013). Invent To Learn: Making, Tinkering, and Engineering the Classroom, Torrance: Constructing Modern Knowledge Press.

[10] Seymour Papert. (1980). "Mindstorms: children, computers, and powerful ideas", Basic Books, Vol.12 No.4, pp. 285-286.

[11] Jonassen, D., Howland, J., and Moore, J. (2002). Learning to solve problems with technology:A constructivist perspective. Shanghai: East China Normal University Press.

[12] Lefebvre, H. (1991). The production of space. Oxford : Blackwell.

[13] Carp, J. (2008). “ 'Ground-Truthing' Representations of Social Space : Using Lefebvre's Conceptual Triad" , Journal of Planning Education and Research, Vol.28 No.2, pp. 129 - 142

[14] Merrifield, A. (2006). Henri Lefebvre: a critical introduction. New York : Routledge.

[15] Johnson, L., Adams Becker, S., Estrada, V., and Freeman, A. (2015), NMC Horizon Report: 2015 higher education edition. Austin, Texas: The New Media Consortium. 